\title{
Dissection of ascending thoracic aorta complicated by cardiac tamponade
}

Two cases of cardiac tamponade caused by dissections of the ascending thoracic aorta are described. Despite uneventul induction of anaesthesia one patient exsanguinated following sternotomy and release of pericardial tamponade as the resulting increase in blood pressure caused aortic rupture. The second patient was managed with femoral-femoral bypass, propranolol and vasodilators prior to sternotomy to avoid this complication, and he survived. The anaesthetic management of a patient with cardiac tamponade is directed towards mainraining cardiac filling pressures and contractility. When the tamponade is released the sudden increase in cardiac output and blood pressure may cause the already weakened aorta to rupture.

\section{Key words}

ANAESTHESIA: cardiovascular, thoracic; COMPLICATIONS: aortic dissection, tamponade; SURGERY: aneurysm, aorta, femoral-femoral bypass, thoracic.

From The Departments of Anaesthesia and Cardiovascular Surgery, Toronto General Hospital, Toronto, Ontario.

Address correspondence to: Dr. P.H. Norman, Department of Anaesthesia, Toronto General Hospital, 200 Elizabeth Street, Toronto, Ontario, M5G $2 \mathrm{C} 4$.
Anaesthesia in a patient with a dissecting thoracic aneurysm or, more correctly, an aortic dissection, demands a smooth induction sequence and careful maintenance. ${ }^{1}$ Increases in cardiac output and blood pressure may cause further aortic dissection or rupture. A known complication of thoracic aortic dissection is rupture into the pericardium with the rapid development of cardiac tamponade. ${ }^{2}$ Once tamponade has occurred the anaesthetic management becomes more complex as any depression of myocardial contractility or decrease in venous retum or heart rate must be avoided. ${ }^{3}$ Hazards to the patient occur not only at induction of anaesthesia, but also later in the operation.

At some stage of the operation, often stemotomy, the cardiac tamponade will be acutely relieved. The resulting increase in cardiac output and blood pressure is caused by a return of normal cardiac function during light anaesthesia which maintains cardiac reactivity and contractility. The sudden increase in aortic wall tension may cause the rupture of the already dissected aortic wall.

Two patients with ascending thoracic aortic dissections and cardiac tamponade are described.

\section{Case report \#1}

A 51-year-old male was admitted following the onset of severe chest pain associated with collapse. He had a ten-year history of hypertension treated with propranolol, and was a smoker. In the emergency room he was conscious but hypotensive and diaphoretic. $\mathrm{He}$ was resuscitated with three $\mathrm{L}$ saline and high dose dopamine which resulted in a systolic blood pressure of $100 \mathrm{mmHg}$. Subsequently during angiography he had a respiratory arrest treated successfully with tracheal intubation and pulmonary ventilation. Angiography demonstrated dissection of the ascending, transverse and descending aorta with retrograde dissection causing cardiac tamponade and involvement of the left main coronary artery.

On arrival in the operating room the systolic BP was 68 $\mathrm{mmHg}$. Anaesthesia was induced with $4000 \mu \mathrm{g}$ fentanyl and $10 \mathrm{mg}$ pancuronium bromide. A flow-directed, balloon-tipped catheter was inserted through a right 
internal jugular approach. The pulmonary artery pressures were $60 / 40 \mathrm{mmHg}$. At the time of sternotomy 50 minutes later, the cardiac tamponade was acutely released when the sternal saw incised through the pericardium. This resulted in a sudden increase in systolic blood pressure from $110 \mathrm{mmHg}$ to $160 \mathrm{mmHg}$, and the aorta burst which resulted in exsanguination and death.

\section{Case report \#2}

A 79 -year-old, $70 \mathrm{~kg}, 173 \mathrm{~cm}$ male was admitted with a history of sudden onset of retrosternal chest pain associated with diaphoresis and nausea. He had a history of hypertension treated with alphamethyldopa and was an ex-smoker.

Physical examination preoperatively revealed a blood pressure of $110 / 78 \mathrm{mmHg}$ and a heart rate of $84 \mathrm{~b} \cdot \mathrm{min}^{-1}$. Jugular venous pressure was $6-8 \mathrm{~cm}$ above the sternal angle with positive Kussmaul's sign and positive hepatojugular reflux. His extremities were cold and clammy. The ECG revealed S-T elevation anteriorly and S-T depression inferiorly. A chest $x$-ray showed pulmonary congestion as well as increased heart size. A 2D-echocardiogram revealed a large pericardial effusion with right ventricular systolic and diastolic collapse. The aortic root was enlarged at $35 \mathrm{~mm}$. A dynamic CT scan confirmed the presence of a large pericardial effusion as well as a type A dissection of the ascending aorta.

After emergency anaesthetic evaluation he was transferred to the operating room. Two peripheral IV cannulae and a left radial arterial line were in situ. A $14 \mathrm{~g}$ intravenous cannula and an external jugular, flowdirected, balloon-tipped thermodilution catheter were established using $10 \mathrm{mg}$ ketamine hydrochloride as temporary sedation. The pre-induction blood pressure was $140 / 80 \mathrm{mmHg}$, heart rate was $80 \mathrm{~b} \cdot \mathrm{min}^{-1}$ and cardiac output was $2.55 \mathrm{~L} \cdot \mathrm{M}^{-2}$. The central venous pressure was $22 \mathrm{mmHg}$, pulmonary artery pressure $45 / 22 \mathrm{mmHg}$, and pulmonary capillary wedge pressure $20 \mathrm{mmHg}$. These pressures demonstrated the equalization of diastolic pressures with tamponade.

Induction of anaesthesia was accomplished with 1000 $\mu \mathrm{g}$ fentanyl, $10 \mathrm{mg}$ pancuronium bromide, and $40 \mathrm{mg}$ ketamine hydrochloride. There was no significant haemodynamic change with induction, the cardiac output remaining unchanged at $2.55 \mathrm{~L} \cdot \mathrm{M}^{-2}$ and the blood pressure at $145 / 80 \mathrm{mmHg}$.

The initial surgical manoeuvre was to establish femoral-femoral bypass in an attempt to prevent a sudden increase in cardiac output and blood pressure in the event of acute pericardial rupture with release of the tamponade during sternotomy. The patient was fully heparinized. At the time of sternotomy the blood pressure was $130 / 70$
$\mathrm{mmHg}$ and with knowledge of the previous case it was decided to depress the patient's myocardium intentionally despite the presence of cardiac tamponade. Therefore 2 $\mathrm{mg}$ propranolol was given as well as two boluses of 0.8 $\mathrm{mg}$ nitroglycerin, $10 \mathrm{mg}$ diazepam and $300 \mu \mathrm{g}$ fentanyl citrate. After an initial decrease to $100 \mathrm{mmHg}$, the BP increased to $150 / 80 \mathrm{mmHg}$ following sternotomy again with accidental pericardiotomy although no aortic rupture occurred. The rapid sequence of events precluded measurement of cardiac output.

A right atrial cannula was inserted and then, under cardio-pulmonary bypass with blood cardioplegia, the almost complete circumferential tear of the ascending aorta was repaired using an interpositional graft. The aortic valve and coronary arteries were found to be intact.

Weaning from bypass was routine and uneventful. The cardiac output had increased to $3.55 \mathrm{~L} \cdot \mathrm{M}^{-2}$. The recovery was complicated by a mild left leg paresis thought to be due to a right cerebral embolism or a partial anterior cord syndrome. This had almost completely resolved before discharge from hospital.

\section{Discussion}

The concerns of induction of anaesthesia in a patient with cardiac tamponade are different from those for a patient with a dissection of the ascending thoracic aorta. ${ }^{2}$ The former requires maintenance of cardiac contractility, venous return, and heart rate due to the fixed stroke volume ${ }^{3.4}$ However, the anaesthetic management of a thoracic aortic dissection demands a controlled systemic blood pressure and ventricular ejection velocity and these are usually achieved with sodium nitroprusside infusion and beta-blockade. ${ }^{1,5}$

Pericardial rupture and cardiac tamponade are usually the terminal event in untreated thoracic aortic dissection ${ }^{6}$ and are often heralded by the development of pericarditis. ${ }^{\text {? }}$ A patient with the combination of the two conditions presents a major problem for stable induction of anaesthesia. In the two cases presented difficulties occurred not in the induction period but later with the sudden retum of normal cardiac function after the inadvertent, acute drainage of a tense pericardial effusion with median sternotomy. The resultant immediate hypertension and increased cardiac output may cause catastrophic aortic rupture.

A recent review of thoracic aortic dissection did not mention this aspect of the management of these patients. ${ }^{5}$ The institution of femoral-femoral bypass prior to sternotomy allows some decrease of the wall tension of the thoracic aorta and makes it possible to maintain some cardiac output in the event of aortic rupture. Still it was necessary to "deepen" the anaesthesia, and use both 
vasodilatation and beta blockade to prevent rises in arterial pressure and cardiac output which may have precipitated aortic rupture.

The potential requirement for vasodilators and negative inotropic agents in a patient with cardiac tamponade due to thoracic aortic dissection is not obvious especially since these drugs need to be given before sternotomy for maximum protection from possible aortic rupture after release of the tamponade. However, one of the cases presented indicates the possible unfortunate outcome if this is not done, although this approach is also dangerous because of the possibility of resultant severe hypotension. Pre-existing femoral-femoral bypass provides some protection against this complication. Inspection of the lateral chest $x$-ray may be useful in predicting whether sternotomy will incise the pericardium.

If the femoral cannulae are inserted under local anaesthesia prior to surgery then the option of femoralfemoral bypass is available in case of cardiovascular instability. Also in the event of further aortic dissection and rupture after sternotomy a pump sucker may be used to increase venous return and allow "sucker-femoral" bypass until a right atrial cannula is inserted.

It has been suggested that optimal anaesthetic management of pericardial tamponade includes sub-xiphoid drainage of the tamponade under local anaesthesia prior to induction of general anaesthesia. ${ }^{3}$ In the presence of aortic dissection this may be hazardous and should not be done without careful consideration.

In summary, two cases of cardiac tamponade complicating thoracic aortic dissection are presented. One died due to aortic rupture following acute relief of the tamponade with inadvertent pericardiotomy during sternotomy. The other, managed with femoral-femoral bypass and vasodilatation and beta-blockade, survived without intraoperative rupture despite also having relief of the tamponade with sternotomy.

\section{References}

1 Dunbar RH. Thoracic Aneurysms. In: Kaplan JA

(Ed.). Cardiac Anaesthesia. Grune \& Stratton 1979; $369-76$.

2 Bond DM, Milme B, Pym J, Sandler D. Cardiac tamponade complicating anaesthetic induction for repair of ascend. ing aorta dissection. Can J Anaesth 1987; 34: 291-3.

3 Lake CL.Anesthesia and pericardial disease. Anesth Analg 1983; 62: 431-43.

4 Kaplan JA. Pericardial diseases. In: Kaplan JA (Ed.). Cardiac Anaesthesia. Grune \& Stratton 1979: 491-6.

5 Ergin MA, Galla JD, Lansman S, Griepp RB. Acute dissections of the aorta. I $n$ : Surgical Clinics of North America. 1985; 65: 721-38.

6 Fraser AG, Passani S, Hayward MWJ. Chronic proximal aortic dissection presenting as tamponade after 16 years. Br Heart J 1987; 58: 166-9.

7 Saner HE, Gobel FL, Nicoloff DM, Edwards JE. Aortic dissection presenting as pericarditis, Chest 1987; 91 :

71-4.

\section{Résumé}

Le traitement d'une tamponnade cardiaque causeée par la dissection de l'aorte ascendante peut être délicat. Malgré une induction anesthésique sans probleme, un de nos patients a saigné à mort quand, suite à la sternotomie et d la décompression du péricarde. la pression artérielle a augmenté, rupturant l'aorte. Dans un cas semblable, nous avons utilisé un système de circulation extra-corporelle fémoro-fémoral, du propranolol et des vasodilatateurs juste avant la sternotomie, sans complication cette fois. Avec une tamponnade cardiaque, l'on se doit de promouvoir le remplissage et la contractilité du coeur cependant, lors de la décompression, il faut prendre garde d une augmentation rapide du débit cardiaque et de la pression artérielle mettant en péril une aorte fragile. 